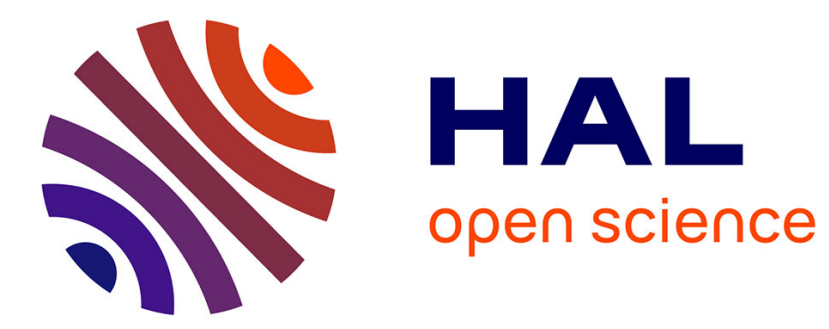

\title{
Refractoriness, Microstructures and High Temperature Oxidation of TaC-Reinforced Iron-Based Alloys Protected by Chromium-Rich Coatings
}

Grégory Michel, Patrice Berthod, Michel Vilasi, Pierre Steinmetz

\section{- To cite this version:}

Grégory Michel, Patrice Berthod, Michel Vilasi, Pierre Steinmetz. Refractoriness, Microstructures and High Temperature Oxidation of TaC-Reinforced Iron-Based Alloys Protected by Chromium-Rich Coatings. Advances in Science and Technology, 2010, 72, pp.53-58. 10.4028/www.scientific.net/AST.72.53 . hal-02482373

\section{HAL Id: hal-02482373 \\ https://hal.science/hal-02482373}

Submitted on 18 Feb 2020

HAL is a multi-disciplinary open access archive for the deposit and dissemination of scientific research documents, whether they are published or not. The documents may come from teaching and research institutions in France or abroad, or from public or private research centers.
L'archive ouverte pluridisciplinaire HAL, est destinée au dépôt et à la diffusion de documents scientifiques de niveau recherche, publiés ou non, émanant des établissements d'enseignement et de recherche français ou étrangers, des laboratoires publics ou privés. 


\title{
Refractoriness, Microstructures and High Temperature Oxidation of TaC-reinforced Iron-based Alloys Protected by Chromium-rich Coatings
}

\author{
Grégory Michel $^{1, a}$, Patrice Berthod ${ }^{1, b}$, Michel Vilasi $^{1, c}$ and Pierre Steinmetz ${ }^{1, d}$ \\ ${ }^{1}$ Institut Jean Lamour, Department 2, Faculty of Science and Techniques, Nancy- \\ University, BP 70239, Vandoeuvre-les-Nancy, France \\ agregory.michel@Icsm.uhp-nancy.fr, bpatrice.berthod@lcsm.uhp-nancy.fr, \\ 'michel.vilasi@lcsm.uhp-nancy.fr, ${ }^{d}$ pierre.steinmetz@lcsm.uhp-nancy.fr
}

Post-print of the article Advances in Science and Technology Vol. 72 (2010) pp 53-58. doi:10.4028/www.scientific.net/AST.72.53

Keywords: Iron-based alloys, tantalum carbides, pack-cementation, chromium, high temperature oxidation

\begin{abstract}
In some cases chromium, necessary for the resistance to hot corrosion, unfortunately tends to lower the solidus temperature of alloys destined to high temperature applications. However a decrease of its content in the bulk can be allowed by a Cr-enrichment of the alloys sub-surfaces. To examine this possibility in the case of refractory TaC-strengthened iron-based alloys, three $\{\mathrm{Fe}$ (bal.) $-10 \mathrm{Cr}-0.2$ or $0.4 \mathrm{C}-3$ or $6 \mathrm{Ta}\}$ - alloys were elaborated by foundry in inert atmosphere and subjected to $\mathrm{Cr}$ deposit and inwards diffusion by a pack-cementation process. Bulk and subsurface microstructures examinations and concentrations profiles were performed after each step of elaboration of the future coated alloys as well as after a 50 hours $/ 1000^{\circ} \mathrm{C}$ oxidation test in air. A $500 \mu \mathrm{m}$-deep carbide-free sub-surface with a chromium content twice the bulk one was obtained for the 0.2C-3Ta and 0.4C-6Ta alloys (less deep for the 0.4C-3Ta alloy) and allowed the alloys resisting high temperature oxidation.
\end{abstract}




\section{Introduction}

When exposed to high temperature in air or in other oxidizing atmospheres, metallic pieces are subjected to more or less rapid oxidation which limits their lifetime [1]. To resist this phenomenon refractory alloys usually contain aluminum (e.g. most of Ni-based alloys), chromium (e.g. most Cobased alloys) or silicon (e.g. $\mathrm{MoSi}_{2}$ alloys), which allows the development of a continuous protective alumina $\left(\mathrm{Al}_{2} \mathrm{O}_{3}\right)$, chromia $\left(\mathrm{Cr}_{2} \mathrm{O}_{3}\right)$ or silica $\left(\mathrm{SiO}_{2}\right)$ layer on their surface, respectively [2]. In some cases the alloys cannot contain sufficiently high quantities of these elements, for example to maintain a high level of refractoriness and/or of creep resistance. To keep a good resistance against high temperature oxidation the alloys need then to be covered by protective coatings which can be created by Physical Vapor Deposition or Chemical Vapor Deposition. A CVD process commonly used is pack-cementation, which can be used for surface enrichment in $\mathrm{Cr}$ [3] as well as in $\mathrm{Al}$ [4] and in $\mathrm{Si}$ [5], or even in two of these elements together [6,7].

There are specific applications for which resistance against high temperature corrosion must be achieved exclusively by a chromia scale, for instance when some parts of the metallic piece are simultaneously also in contact with molten salts or glass (by which alumina and silica scales are especially deteriorated). High chromium contents are then required in the sub-surface.

In this work three iron-based alloys, especially refractory and reinforced by tantalum carbides, were considered. They contain significantly lower chromium contents (wt.\%Cr) by comparison with similar alloys previously studied [8] which were oxidation-resistant [9] thanks to chromium contents much higher $(30 \mathrm{wt} . \% \mathrm{Cr})$. These low-chromium iron-based alloys must be protected against oxidation and it was tried here to enrich them in chromium by pack-cementation and to test the high temperature oxidation behavior of the obtained coated alloys.

\section{Experimental}

Elaboration of the alloys and microstructure observations. Three iron-based alloys were synthesized by high frequency induction melting (CELES) under inert atmosphere (300mbars Argon), from pure elements: $\mathrm{Fe}, \mathrm{Cr}$, Ta and $\mathrm{C}$ (graphite). The first alloy, named FeTa1, is a $\mathrm{Fe}$ (bal.)-0.2C-10Cr-3Ta alloy (in wt.\%). The second one and the third one, FeTa2 and FeTa3, have as chemical composition Fe(bal.)-0.4C-10Cr-3Ta and Fe(bal.)-0.4C-10Cr-6Ta respectively. After a first fusion of the charge (about $30 \mathrm{~g}$ ) and solidification in the water-cooled copper crucible of the HF furnace, the ingots were re-melted and poured in a cylindrical copper mould. The new ingots, with a cylindrical shape (length $50 \mathrm{~mm} \times$ diameter $10 \mathrm{~mm}$ ), were cut in order to obtain several disks (diameter $10 \mathrm{~mm} \times$ thickness $2.5 \mathrm{~mm}$ ). Per alloy one of these samples was mounted in resin and polished, first using 240 -grit to 1200 -grit $\mathrm{SiC}$ papers, and second using $1 \mu \mathrm{m}$ alumina paste. These mounted samples allowed controlling the initial microstructure, using a Scanning Electron Microscope (Philips XL30) in Back Scattered Electrons mode and under 20kV (acceleration voltage). Three other disks were cut: one for a cementation only and two for a cementation followed by a diffusion heat treatment.

Cr-coating by the pack-cementation technique. For the cementation the disks were polished up to 1200-grit paper, then placed in a silica bulb with the pack containing the halide activator (powder of $\left.\mathrm{CrCl}_{3}\right)$ and the master alloy/cement (powder of pure $\mathrm{Cr}$ ) mixed with an inert powder $\left(\mathrm{Al}_{2} \mathrm{O}_{3}\right)$. Secondary vacuum was performed in the silica bulb containing the alloy disks and the pack, the bulb was closed and put in a furnace at $1050^{\circ} \mathrm{C}$ for $15 \mathrm{~h}$. After cooling the disks were washed under ethanol and ultrasonically cleaned, to remove grains of cement or of alumina still present on the surface. For each alloy a cemented disk was taken for metallographic characterization while two cemented disks underwent an additional heat treatment at $1200^{\circ} \mathrm{C}$ for 75 hours to promote a deeper enrichment in chromium by inwards diffusion. The enrichment in chromium on surface and on the sub-surface, just after cementation and after the diffusion heat-treatment, was characterized by 
performing WDS microanalysis profiles (Cameca SX 50 or SX100 microprobes) from the external surface inwards the bulk, over a depth equal to $500 \mu \mathrm{m}$.

Tests of oxidation at high temperature. The behavior of the coated alloys (cemented and heat treated) in high temperature oxidation was studied by exposing the disk samples to air at $1000^{\circ} \mathrm{C}$ for 50 hours in a tubular furnace. After cooling in furnace, the oxidized samples were prepared as the other metallographic samples (however after electrolytic nickel coating to protect the external oxide scales during cutting and polishing), observed with the SEM in BSE mode (external oxides if still present and sub-surface deterioration). Concentration profiles perpendicular to surface and inwards the bulk over $500 \mu \mathrm{m}$ were also performed.

\section{Results et discussion}

Refractoriness and microstructure of the alloys. Before elaborations thermodynamic calculations were performed in order to assess the solidus temperatures of such low-chromium bulk alloys. This was done using Thermo-Calc version $\mathrm{N}$ with a database developed from the SSOL one with addition of thermodynamic description of sub-systems including notably tantalum. Some details about this database were already given in a previous work [8]. The 10wt.\%Cr-containing FeTa1, FeTa2 and FeTa3 alloys would be effectively more refractory than the homologous alloys containing $30 \mathrm{wt} . \% \mathrm{Cr}$, since the calculated solidus temperature increases from $1469^{\circ} \mathrm{C}(30 \% \mathrm{Cr})$ to $1481^{\circ} \mathrm{C}(10 \% \mathrm{Cr})$ for $\mathrm{FeTa}$, from $1300^{\circ} \mathrm{C}$ to $1436^{\circ} \mathrm{C}$, for $\mathrm{FeTa} 2$ and from $1465^{\circ} \mathrm{C}$ to $1478^{\circ} \mathrm{C}$ for FeTa3. Calculations show that the great increase in $\mathrm{T}_{\text {sol }}$ in the case of FeTa 2 can be relied to the disappearance of chromium carbides (e.g. $3.15 \%$ of $\mathrm{TaC}$ but also $1.60 \%$ of $\mathrm{M}_{23} \mathrm{C}_{6}$ in mass at $1200^{\circ} \mathrm{C}$ if $30 \mathrm{wt} . \% \mathrm{Cr}$, while only $\mathrm{TaC}$ if $10 \mathrm{wt} . \% \mathrm{Cr}$ ), which usually tend to decrease the solidus temperature of superalloys. Calculations also showed that matrix is BCC for all the three FeTa alloys at high temperature if they contain $30 \mathrm{wt} . \% \mathrm{Cr}$ while a significant part of FCC matrix coexists with the BCC matrix in these alloys if only $10 \mathrm{wt} . \% \mathrm{Cr}$ are present, potentially leading to better mechanical properties at high temperature.

The real obtained alloys display dendritic matrixes with more or less tantalum carbides (whiter than matrix when observed with a SEM in BSE mode, Fig. 1). These TaC carbides are initially present in the interdendritic spaces where they formed a eutectic compound with matrix.

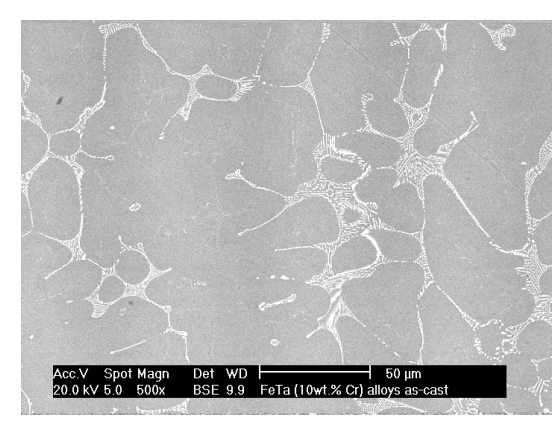

as-cast FeTa1

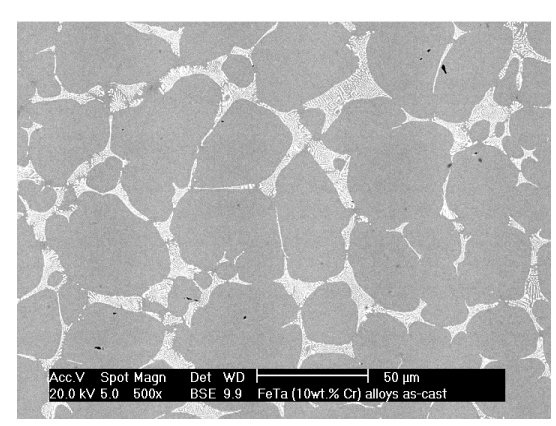

as-cast FeTa2

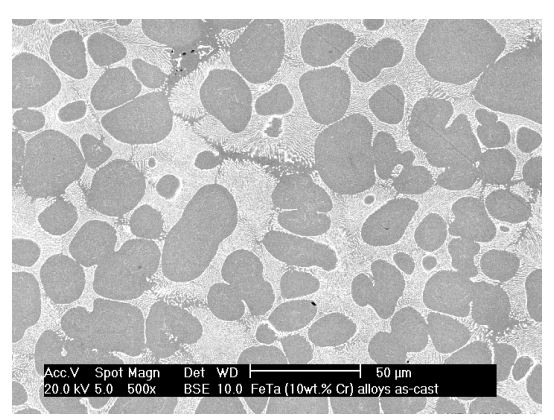

as-cast FeTa3

Fig. 1. As-cast microstructures of the studied alloys

Sub-surface states of the cemented+heat-treated alloys and Cr-enrichment. After cementation and diffusion treatment the $\mathrm{TaC}$ carbides are considerably fragmented (Fig. 2), as earlier seen also for the analogous alloys containing $30 \% \mathrm{Cr}$ after exposure at $1200^{\circ} \mathrm{C}$ for several tens hours [8]. 


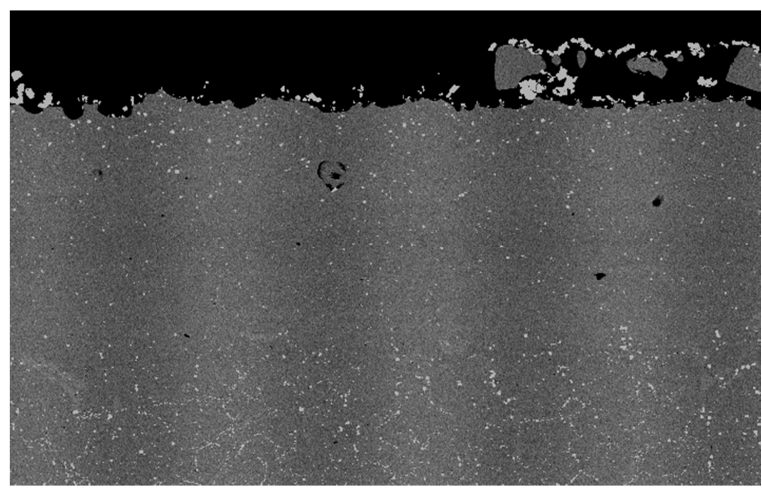

FeTa1

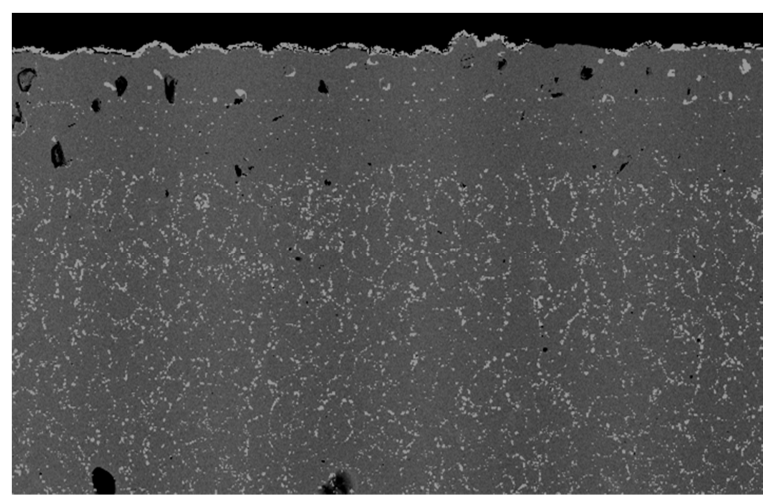

FeTa3

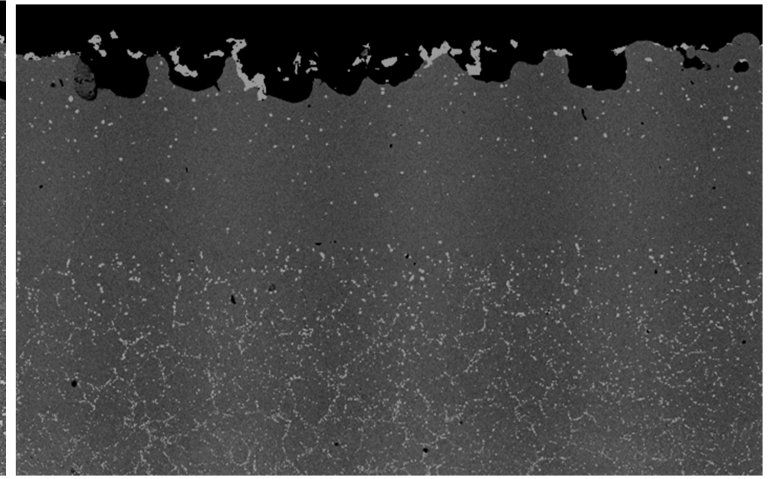

FeTa2

Fig. 2. Microstructures and sub-surface states of the three alloys after cementation and diffusion treatment

The diffusion of chromium inwards the alloys during cementation and heat-treatment led to the growth of a carbide-free zone (similar to the ones generally due to high temperature oxidation of not coated superalloys reinforced by carbides), over which tantalum-rich particles (white) are dispersed. Two WDS concentration profiles were performed per sample and they generally showed a good reproducibility. Only one of them is given for \{each alloy - treatment $\}$ couple in Fig. 3. After cementation the depth of enrichment in $\mathrm{Cr}$ is more or less $500 \mu \mathrm{m}$ (continuous decrease from about $50 \mathrm{wt} . \% \mathrm{Cr}$ on surface down to almost $10 \mathrm{wt} . \%$ ) for FeTa1, about only $350 \mu \mathrm{m}$ for FeTa2 (decrease from only $25 \mathrm{wt} . \%$ down to about $18 \mathrm{wt} . \%$ then fall to $10 \mathrm{wt} . \%$ ) and again progressive decrease for FeTa3 very similarly to FeTa1. The diffusion treatment led to a deeper inwards diffusion of these quantities of chromium, with consequently a lowering of the chromium contents in the sub-surfaces, down to about $20 \mathrm{wt}$ \% for the two alloys but limited to the initial enriched depth in the case of FeTa2. Thus, cementation followed by diffusion treatment led to a $\mathrm{Cr}$ content twice the initial one over a significant depth. 

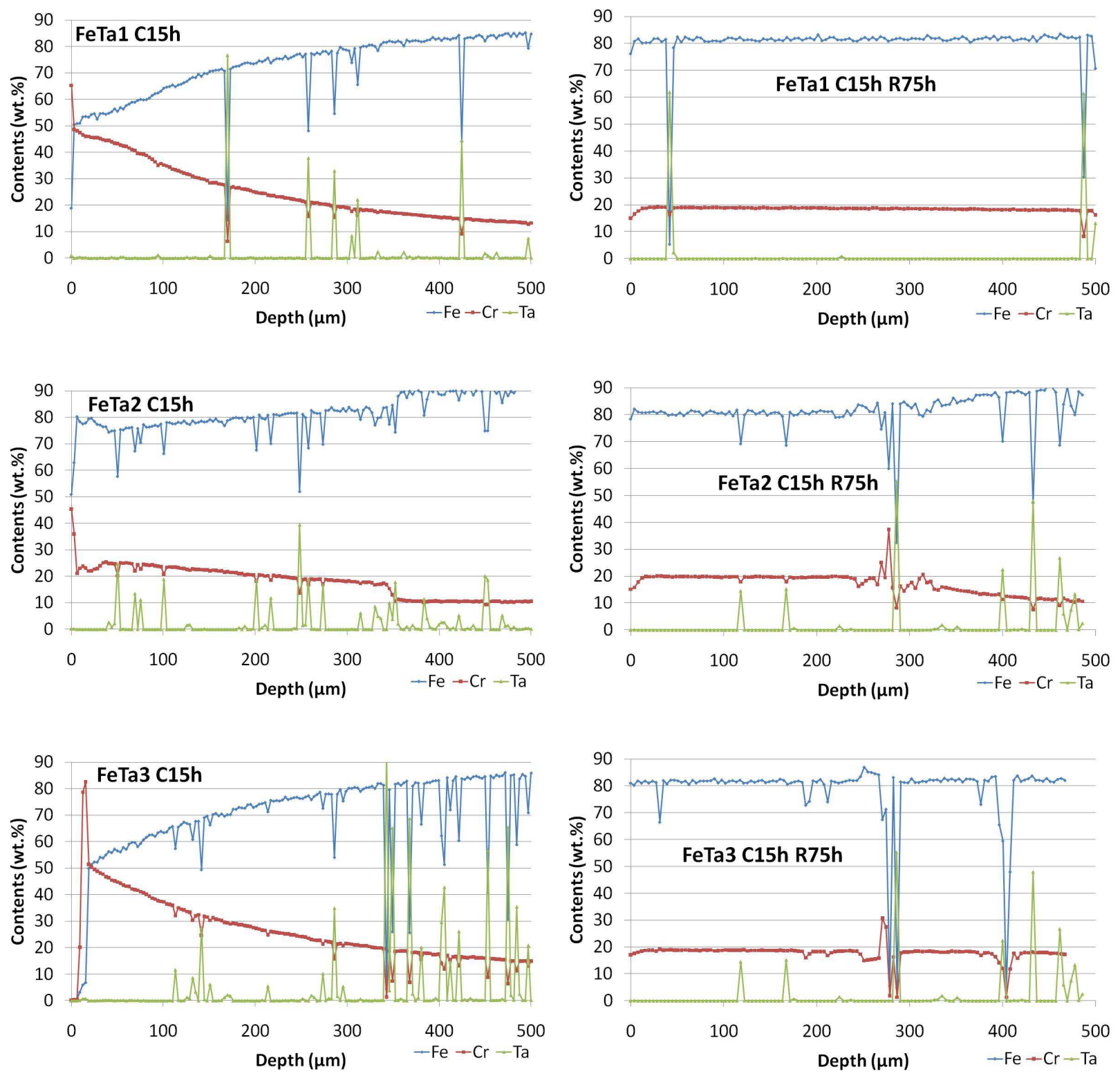

Fig. 3. Concentration WDS profiles after cementation (left hand) and after cementation + diffusion treatment (right hand), for the three alloys.

High temperature oxidation tests. The cemented and heat-treated samples were subjected to oxidation by air at $1000^{\circ} \mathrm{C}$ for 50 hours. The states of the oxidized surfaces are illustrated in Fig. 4 by SEM/BSE micrographs and WDS concentrations profiles (one of the two performed in each case). The surface deterioration by high temperature oxidation was still limited but among the partial oxides scales remaining on surface after cooling there were a consequent proportion of oxides of iron or of $\mathrm{Fe}$ and $\mathrm{Cr}$ together (spinels), without any continuous protective chromia. During oxidation the chromium quantity exceeding the $10 \mathrm{wt} \%$ bulk content after the \{cementation+diffusion\}-treatment in the first $400 \mu \mathrm{m}$-depth has decreased from $27.0 \pm 0.7 \mathrm{mg} / \mathrm{cm}^{2}$ down to $24.7 \pm 0.5 \mathrm{wt} . \% \mathrm{Cr}$ for FeTa1, from $27.5 \pm 1.6 \mathrm{mg} / \mathrm{cm}^{2}$ down to $22.9 \pm 5.9$ wt. $\% \mathrm{Cr}$ for FeTa2, 
and from $25.5 \mathrm{mg} / \mathrm{cm}^{2}$ down to $23.4 \pm 1.7 \mathrm{wt} . \% \mathrm{Cr}$ for FeTa3. Catastrophic oxidation appeared imminent, especially for the FeTa1 alloy which displays surface chromium contents very low $(9.7 \pm 0.6$ wt. $\% \mathrm{Cr}$, against $12.4 \pm 3.7 \mathrm{wt} . \% \mathrm{Cr}$ for $\mathrm{FeTa} 2$ and $16.5 \pm 1.6 \mathrm{wt} . \% \mathrm{Cr}$ for $\mathrm{FeTa} 3)$, e.g. decreased down to the bulk one.
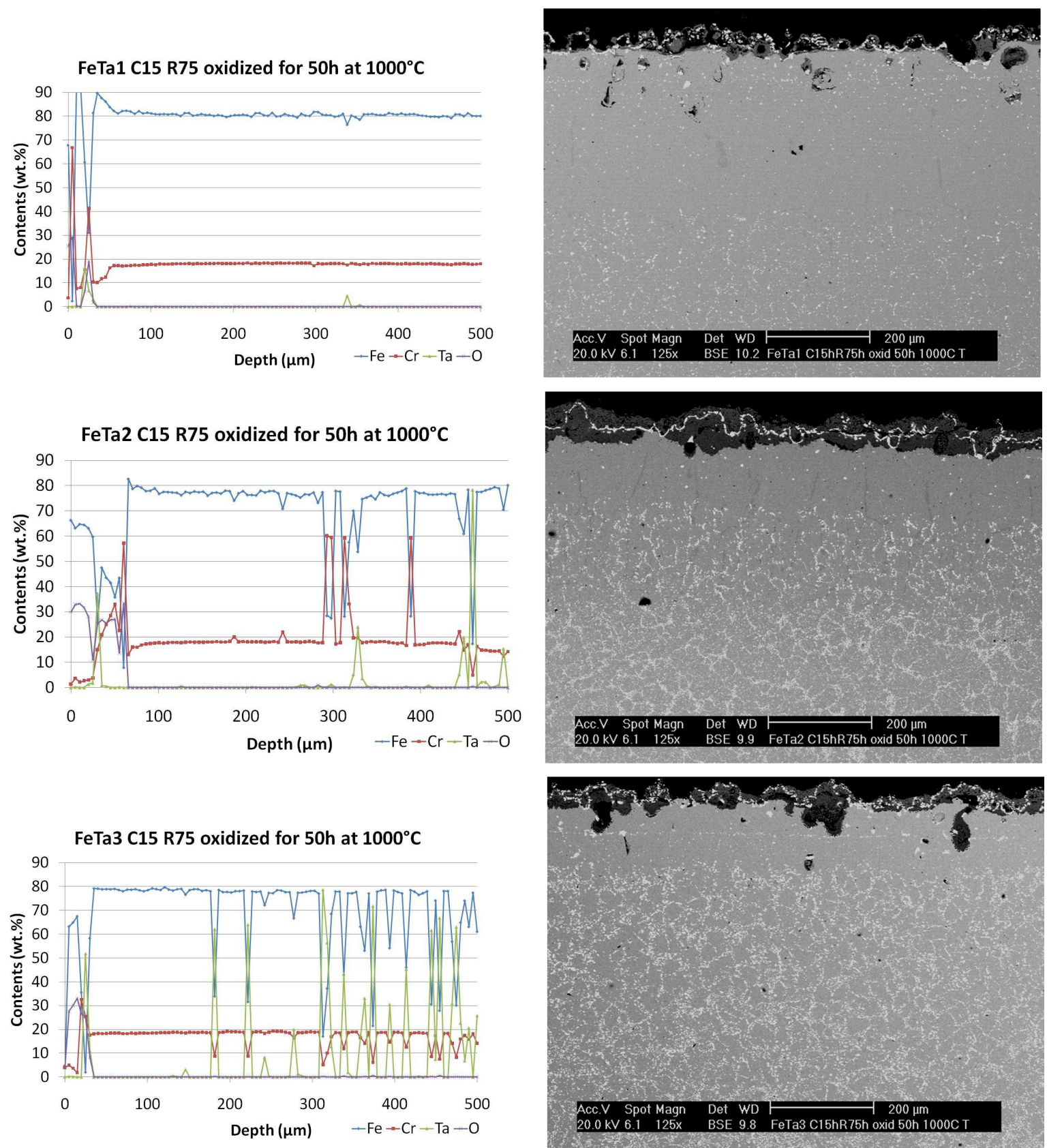

Fig. 4. Surface states and sub-surface concentration profiles of the coated samples after oxidation 


\section{Conclusions}

The refractoriness of chromium-containing iron-based alloys reinforced by tantalum carbides can be increased by lowering their bulk chromium content. More or less significant increases in fusion's start temperatures can be expected by choosing $10 \mathrm{wt} . \% \mathrm{Cr}$ instead of the $30 \mathrm{wt} . \% \mathrm{Cr}$ efficient to ensure good resistance against oxidation at high temperature. The sub-surface of such alloys impoverished in chromium can be obviously enriched again in chromium by pack-cementation, but the depth of this enrichment may depend on the carbon and tantalum contents (tantalum/carbon balance) in the bulk. With the procedure applied in this work the obtained chromium content in the sub-surface is twice the initial one, which appeared not high enough to guarantee a good behavior in high temperature oxidation for long durations. Thus, the parameters of cementation and diffusion heat treatment remain to be optimized for improving the sub-surface Cr-reservoir for these family of alloys, and then for allowing them to longer resist oxidation at high temperature.

\section{References}

[1] E.F. Bradley: Superalloys: A technical guide (ASM International, 1988).

[2] P. Kofstad: High Temperature Corrosion (Elsevier, 1988).

[3] X. Peng, J. Yan, Z. Dong, C. Xu and F. Wang: Corrosion Science 52(5) (2010), p. 1863

[4] M. Reza Bateni, S. Shaw, P. Wei and A. Petric: Materials and Manufacturing Processes 24(6) (2009), p. 626

[5] X. Tian and X. Guo: Surface and Coatings Technology 203(9) (2009), p. 1161

[6] B. Gaillard-Allemand, M. Vilasi, T. Belmonte and J. Steinmetz: Materials Science Forum Vol. 369-372 (2001), p. 727

[7] M. Vilasi, M. François, R. Podor and J. Steinmetz : Journal of Alloys and Compounds 264(1-2) (1998), p. 244

[8] P. Berthod, Y. Hamini, L. Aranda and L. Héricher: Calphad 31 (2007), p. 351.

[9] P. Berthod, Y. Hamini and L. Aranda: Materials Science Forum Vol. 595-598 (2008), p. 861. 